\title{
Evaluation of the Heat Recovery Potential by Using an Exergy Analysis Approach to Improve Energy Efficiency of Industrial Refrigeration Systems
}

\author{
Kamran Taheri and Rainer Gadow
}

\begin{abstract}
This work applies an exergy analysis approach to investigate the performance and waste heat recovery potential of an industrial air-cooled screw chiller. To reduce the factory overall primary energy demand, a $410 \mathrm{~kW}$ chiller with $274 \mathrm{~kW}$ heat reclaim capability for generation of $70^{\circ} \mathrm{C}$ hot water, was analyzed. The evaluation was established based on system irreversibility and Total Recovery Potential (TRP) or exergy efficiency of the recovered heat.

For evaluation of the total recovery potential, exergy efficiency of the refrigeration system with heat recovery was expressed in terms of recovery efficiency and effectiveness to identify the importance and contribution of each term to improve the exergy efficiency. The analysis was conducted for various cooling capacity for the analysis boundary including the refrigeration system and the suitable used point e.g. water or space heating.

It was concluded that due to the low quality of the waste heat from the refrigeration system, total recovery potential or exergy efficiency of the recovered heat was more a question of effectiveness rather than merely an efficiency-based evaluation. Therefore TRP was low, approximately 6-12\%, even though the recovery efficiency reached up to $94 \%$ for the half load capacity. Also it was observed that due to the higher compressor power demand for the system with heat recovery, COP and $\mathrm{COP}_{\mathrm{Ex}}$ were 3.43 and 3 respectively which were quite lower than of the values for conventional refrigeration system.
\end{abstract}

Index Terms-Exergy efficiency, air-cooled chiller, total recovery potential, waste heat recovery.

\section{INTRODUCTION}

In manufacturing sectors heat is produced and consumed for many purposes such as component testing, process preheating and etc. In regular manufacturing, waste heat is an unavoidable and necessary joint output [1] and it should be removed through chiller and refrigeration systems. Recovery and reuse of the waste heat through the application of chiller systems with heat reclaim capabilities and providing as the useful energy for space and water heating purposes will reduce total energy consumption for the factory. Air-cooled chillers have been commonly used to cool down water and other secondary coolants for commercial and industrial

Manuscript received August, 2015; revised January 15, 2016.

Kamran Taheri is with Graduate School of Advanced Manufacturing Engineering, University of Stuttgart, Stuttgart, Germany (e-mail: kamrantaheri86@gmail.com)

Rainer Gadow is with the Institute for Manufacturing Technologies of Ceramic Components, University of Stuttgart, Germany (e-mail: rainer.gadow@ifkb.uni-stuttgart.de). air-conditioning or refrigeration systems.

The majority of the literatures define waste heat simply as heat lost to the environment, often disregarding of its temperature and possibility for reuse [2]. As stated by Bendig $M$ [3] not only the quantity, but also the quality of the heat available at different temperature should be taken into account to be used in secondary process. The quality of low grade waste heat is defined by minimum temperature difference which is needed for the heat exchange and transfer of heat into the heat sink [4].

Evaluating low quality of the waste heat which is exiting by waste water and air streams from a facility for recovery purposes is critical since recovery approach is not economical or even possible in many cases. Heat loss can be large in quantity, but it might not be thermodynamically very significant to be recovered due to the low quality and effectiveness [5]. Preserving the quality of energy and increasing the energy efficiency of refrigeration systems are major concerns to engineers, and the exergy analysis provides the necessary means to determine the quality as well as the extent of degradation of energy during a refrigeration process [6]. Exergy analysis is a powerful analysis tool which indicated the potential energy can be recovered and effectively used in the sink point. Application of exergy analysis for evaluation of waste heat recovery has been studies by many researchers [4], [7]-[10]. According to the exergy analysis and irreversibilities, effectiveness of the energy flows is degraded before it reaches to the use point [11]. Jentsch also proposed the importance of the decomposing exergy efficiency into its quality and quantity components to analyze the behavior of these components individually [12]. This approach gives more transparent exergy-based results by magnifying the impact of individual term on total recovery potential.

Even though many literatures discussed about the performance of the chiller on the basis of exergy [13], few exergetic studies have been focused for the system with heat recovery under different cooling capacities. Also the works cited above shows that the application of the exergy analysis with emphasizing on its constituent components to commercial screw chillers is still lacking. Same as presented approach by Jentsch [12], in this work the exergy efficiency of the waste heat is expressed in terms of recovery efficiency and effectiveness. Recovery efficiency stands for the quantity of the recovered heat and shows the direct saving potential. However the effectiveness corresponds to the quality of the recovered heat. Combination of these terms helps to realize indirect saving potential. 


\section{EXERGY ANALYSIS APPROACH}

For energy and exergy analysis of a system, selection of an appropriate analysis boundary is critical. The aim of this study is to investigate the waste heat recovery potential on the basis of an exergy analysis method for improving the energy efficiency of the factory cooling systems. A closed loop factory model is developed in Fig. 1. As depicted in the model, the unavoidable waste heat from the manufacturing sectors is removed to atmosphere through the cooling systems and the central chiller. The energy content of the heat will be increased through this path due to the additional electrical power used by the cooling systems. Therefore the upgraded heat has potential to be recovered and internally used in the factory for different heating purposes. Fig. 2 shows the internal heat cycle of a refrigeration system.

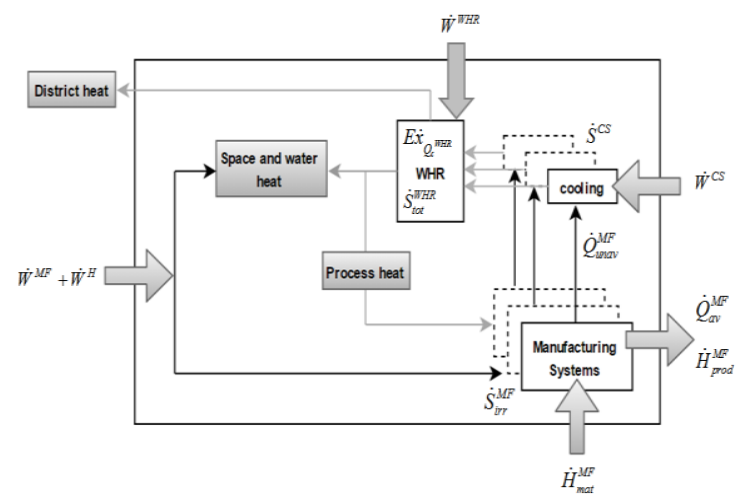

Fig. 1. Factory waste heat recovery model.

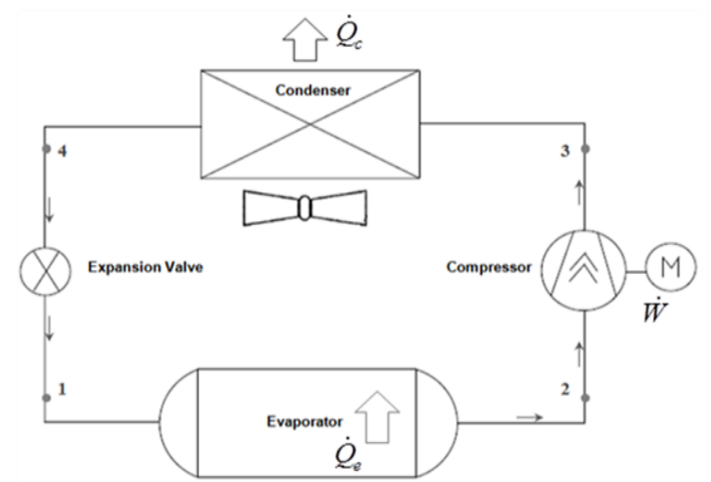

Fig. 2. Schematic of a refrigeration system.

In Fig. 1, $\dot{W}^{M F}, \dot{W}^{H}, \dot{W}^{C S}$ and $\dot{W}^{W H R}$ are the energy consumption $(\mathrm{kW})$ for manufacturing, heating, cooling systems and central refrigeration respectively. $\dot{S}^{M F}, \dot{S}^{C S}$ and $\dot{S}^{W H R}(\mathrm{KJ} / \mathrm{s} . \mathrm{K})$ are the total irreversibilities for the manufacturing processes, their cooling systems and central refrigeration system. However avoidable and unavoidable heat losses are represented by $\dot{Q}_{a v}^{N F}$ and $\dot{Q}_{\text {unav }}^{N F}(\mathrm{~kW}) . E \dot{x}_{Q^{\text {WHR }}}$

$(\mathrm{kW})$ is the amount of heat which can be effectively recovered and reused based on the reference temperature of the used point. The enthalpy transferred by the material flows in the factory is shown by $\dot{H}_{m a t}^{N F}$ and $\dot{H}_{\text {prod }}^{N F}(\mathrm{~kW})$ which is not considered in this study.

From Fig. 2, $\dot{Q}_{C}, \dot{Q}_{e}$ are the condensation and evaporation heat, and $\dot{W}$ is the compressor work. Energy and irreversibility balances for each component is given in Table I.

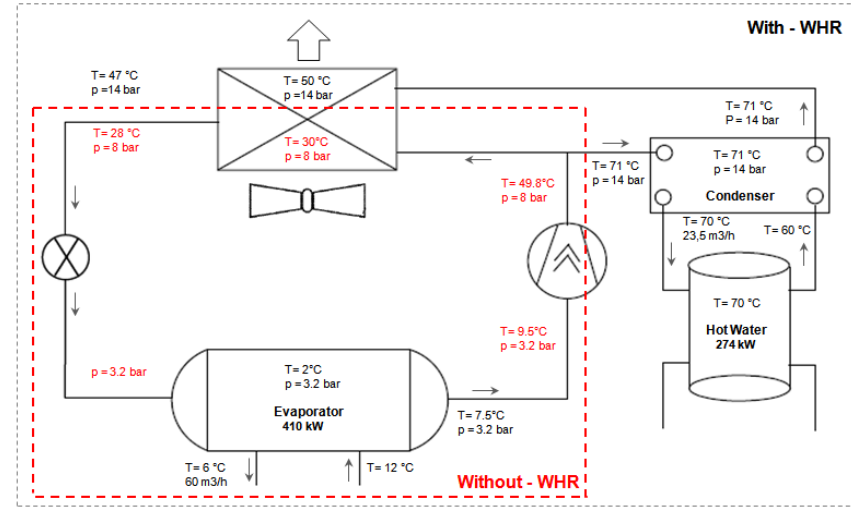

Fig. 3. Magnetization as a function of applied field.

Total system irreversibility $\left(\dot{S}_{\text {tot }}\right)$ is calculated from the irreversibility of the chiller components. $\dot{m}_{r}(\mathrm{Kg} / \mathrm{s})$ is the mass flow rate of the refrigerant and $h_{i}(\mathrm{KJ} / \mathrm{kg})$ represents the enthalpy of the refrigerant in the input and output of each component.

TABLE I: ENERGY AND IRREVERSIBILITY BALANCE FOR REFRIGERATION

\begin{tabular}{lll}
\multicolumn{2}{c}{ SYSTEM } \\
\hline \hline Components & Energy balance & Irreversibilities \\
\hline Compressor & $\dot{\mathrm{W}}_{\mathrm{CO}}=\dot{m}_{r}\left(h_{3}-h_{2}\right)$ & $\dot{\mathrm{I}}_{\mathrm{CO}}=\dot{m}_{r}\left(S_{3}-S_{2}\right)$ \\
& $\dot{\mathrm{Q}}_{C}=\dot{m}_{r}\left(h_{4}-h_{3}\right)=$ & $\dot{\mathrm{I}}_{C O}=\dot{m}_{r}\left(S_{4}-S_{3}\right)-\frac{\dot{Q}_{C C}}{T_{0}}$ \\
& $\dot{m}_{\text {air }}\left(h_{\text {out }}-h_{i n}\right)$ & \\
Condenser & & $\dot{\mathrm{I}}_{E V}=\dot{m}_{r}\left(S_{1}-S_{4}\right)$ \\
valve & $h_{1}=h_{4}$ & \\
& $\dot{\mathrm{Q}}_{\mathrm{e}}=\dot{m}_{r}\left(h_{2}-h_{1}\right)=$ & $\dot{\mathrm{I}}_{e}=\dot{m}_{r}\left(S_{2}-S_{1}\right)-\frac{\dot{Q}_{e}}{T_{0}}$ \\
Evaporator & $\dot{m}_{\text {water }}\left(h_{\text {out }}-h_{\text {in }}\right)$ & \\
&
\end{tabular}

Considering the exchanged heat and system irreversibilities, energetic and exergetic chiller performance are expressed as follow:

$$
\begin{gathered}
C O P=\frac{\dot{Q}_{C}^{W H R}}{\dot{W}} \\
C O P_{E x}=\frac{\dot{Q}_{C}^{W H R}-\dot{S}_{t o t}^{W H R}}{\dot{W}}
\end{gathered}
$$

"Equation (3)," to “(6)," are introduced for evaluation of total recovery potential in order to determine the improvement of the factory energy efficiency and reduction of the energy consumption through recovery approach. Emphasizing the quality of the waste heat, this approach is based on the Carnot factor [3]. Note that the electrical power used by the chiller compressors has the exergy value equal to the energy. Therefore Total Recovery Potential (TRP) can be expressed as the exergy efficiency of the recovered heat and can be obtained through the given equations:

$$
\varepsilon=\frac{\begin{array}{c}
\text { Recovery efficiency } \\
\dot{Q}_{C}^{W H R}
\end{array}}{\dot{W}^{W H R}+\Sigma \dot{W}^{C S}}
$$

Effectiveness

$$
\eta_{\text {eff }}=\frac{E \dot{x}_{\dot{Q}_{C}^{W H R}}}{\dot{Q}_{C}^{W H R}}
$$




$$
\begin{gathered}
\text { Exergy of the recovered heat } \\
E \dot{x}_{\dot{Q}_{C}^{W H R}}=\left(1-\frac{T_{0}}{T}\right) \cdot\left(\dot{Q}_{C}^{W H R}-\dot{S}_{t o t}^{W H R}\right) \\
\text { Total Recovery Potential } \\
T R P=\varepsilon \cdot \eta_{\text {eff }}=\left(\frac{\dot{Q}_{C}^{W H R}}{\dot{W}^{W H R}+\Sigma \dot{W}^{C S}}\right) \cdot\left(\frac{E \dot{x}_{C}^{\text {WHR }}}{\dot{Q}_{C}^{W H R}}\right)
\end{gathered}
$$

where $\varepsilon$ and $\eta_{e f f}$ are defined as the recovery efficiency and effectiveness respectively.

\section{EXPERIMENT RESULTS AND DISCUSSION}

An industrial 410 kW air-cooled screw chiller with R134 a has been investigated. A schematic of the system is shown in Fig. 3. The process parameters are adjusted depends on the evaluation boundary for the conditions with and without waste heat recovery. Physical parameters such as pressure, temperature and refrigerant flow rate as well as compressor power have been influenced by the change in process condition.

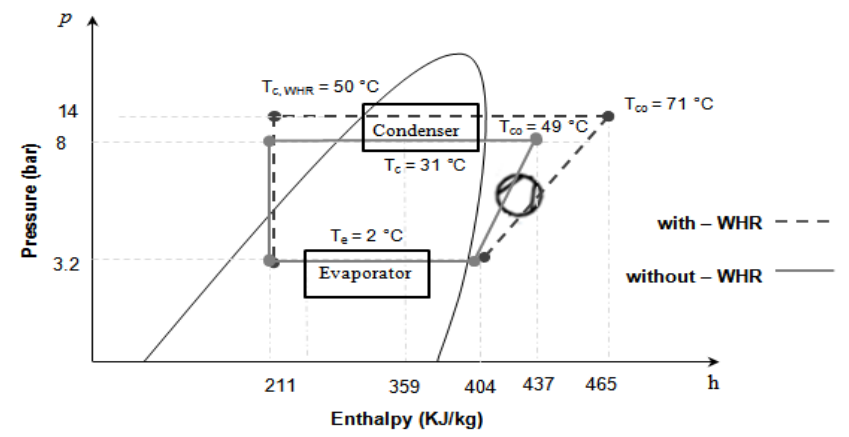

Fig. 4. Pressure-enthalpy diagram of chiller for the conditions with and without WHR.

Refer to Fig. 1 and Fig. 2, $\dot{W}^{W H R}$ is supplied for an adiabatic compression of the refrigerant between states 2 and 3 is varied with the cooling capacity and has been given by the producer and is limited with the compressor properties. The condensation heat, $\dot{Q}_{C}$ is the summation of compressor power and evaporation heat. After removing the condensation heat, the refrigerant makes an adiabatic expansion through the expansion valve between states 4 and 1 . For heat recovery purpose, $274 \mathrm{~kW}$ of the waste heat is reused to generate $70^{\circ} \mathrm{C}$ hot water. To achieve the desired amount of condensation heat, the analysis has been carried out for the ambient temperature, $T_{0}$, range from $23^{\circ} \mathrm{C}$ to $35^{\circ} \mathrm{C}$ (50-100\% cooling capacity). The quest to achieve the desired water temperature, $T$, and capture more heat in the first condenser for the system with heat recovery, the compressor needs to work with higher power demand [14]. This is because at elevated condenser temperature, refrigerant pressure and flow rate will be raised as is depicted in Fig. 3. Increased pressure differential translates into a greater amount of work necessary to compress the refrigerant which reduces the overall chiller performance (COP). This outcome can be understood by examination of a typical refrigeration pressure-enthalpy $(\mathrm{P}-\mathrm{h})$ diagram to uncover the answer. The pressure-enthalpy diagram refers to the examined system for the conditions with and without heat recovery is illustrated in Fig. 4.

For exergetic evaluation of the chiller, this study encompasses the following main contents.

\section{A. Compare the Refrigeration System Performance for the Conditions with and without Waste Heat Recovery (WHR)}

For these analysis, central chiller was assumed as the analyzed boundary. Fig. 5 and Fig. 6 shows the irreversibility and irreversibility ratio of the chiller components for two investigated conditions. The equations provided in the "Table I" are applied for these evaluation. It was assumed an isentropic expansion through expansion valve as the entropy change for R134a was negligible. The total irreversibility of the conventional chiller was $31.2 \mathrm{~kW}$, which was considerably lower than the $66.5 \mathrm{~kW}$ for the chiller integrated with WHR. It was observed that due to the higher pressure and temperature as well as higher refrigerant flow rate for the chiller with WHR, the irreversibilities in evaporator and condeser were increased followed by that of the compressor. There was also an additional irreversibility, approximately 13 $\%$, for the condeser of the hot water.

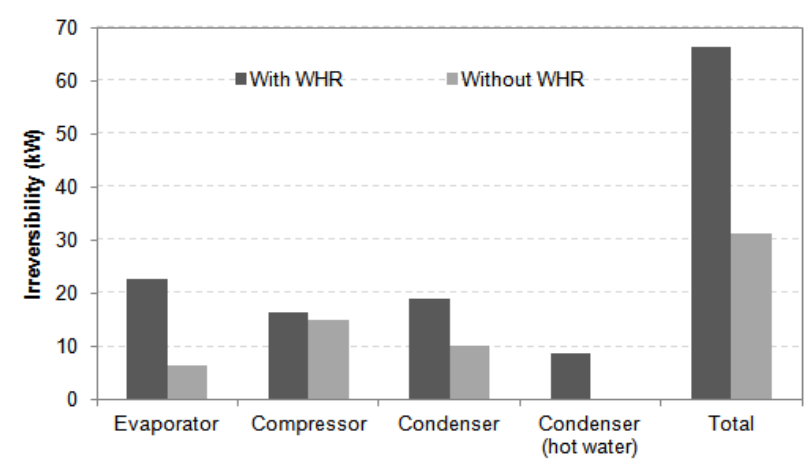

Fig. 5. Comparison of exergy destruction associated with chiller components for chiller with and without WHR.

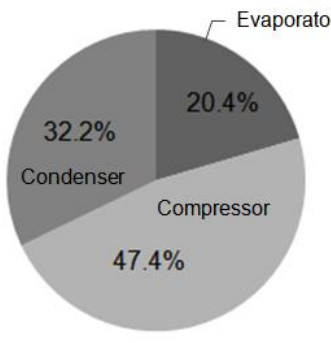

a) Without WHR

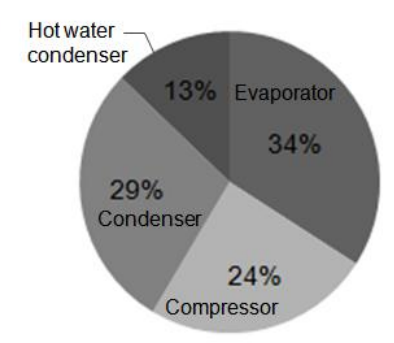

b) With WHR
Fig. 6. Comparison of exergy destruction ratio associated with chiller components; a) without WHR, b) with WHR.

According to the operational system parameters shown in Fig. 3 and the total irreversibilities from Fig. 5, COP and $\mathrm{COP}_{\mathrm{Ex}}$ for both system conditions were calculated based on "(1)," and "(2),". Examining Fig. 7, we find that COP and $\mathrm{COP}_{\mathrm{Ex}}$ for the condition without WHR are 6.3 and 5.9 respectively. However for the system with WHR they are 3.43 and 3. This is because for the same cooling csapacity, the compressor power was increased to achieve the higher condensation temperature for heat recovery purpose. As the temperatures of the condensation heat raises, the chiller efficiency decreases [10]. It was also noticed that due to 
chiller internal irreversibility, $\mathrm{COP}_{\mathrm{Ex}}$ was slightly lower than COP.

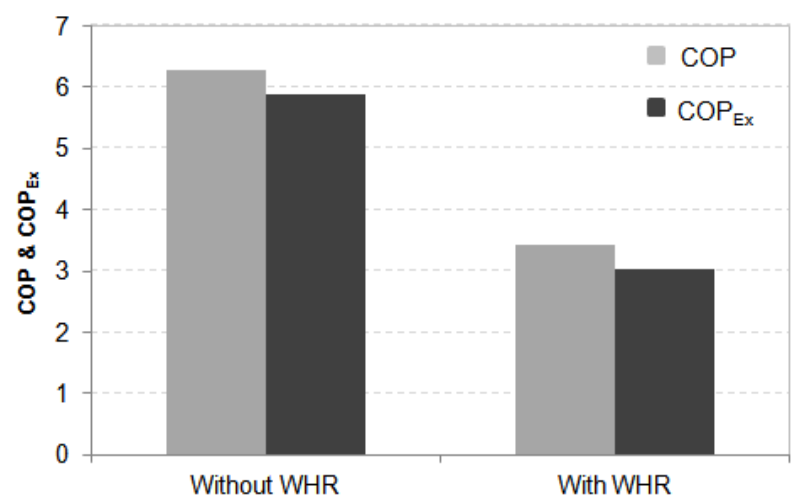

Fig. 7. $\mathrm{COP}$ and $\mathrm{COP}_{\mathrm{Ex}}$ investigation for the chiller with and without WHR.

\section{B. Investigation of the Waste Heat Recovery Potential as a Resource Saving Factor}

To evaluate the total recovery potential as a resource saving factor, the effectiveness of the heat to be used in the sink point was determined in regards with the system internal irreversibilities and ambient temperature according to "(4)," and "(5),". The total waste heat was estimated as a net consumed power of the factory air conditioning systems as the cooling capacity and the central chiller power used. In reference with Fig. 8 the total waste heat is increased by increase of cooling capacity. Even though the power consumtion was increased due to the higher energy consumption by running the more air conditioning at higher ambient temperature and well presented and explained in every company's refrigeration system catalogue.

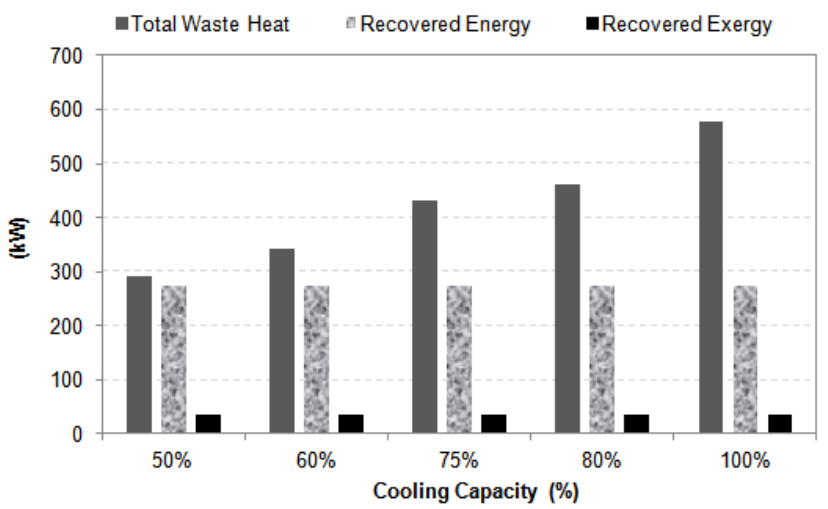

Fig. 8. Total waste heat, recovered energy and recovered exergy for WHR chiller as a function of chiller cooling capacity.

It can also been seen that according to Carnot factor, the recovered exergy is significantly lower than the potential recovered energy. In other words recovered exergy represents the useful amount of heat can be extracted and apply for heating purpose. As mentioned earlier, in this study exergy is expressed in terms of its constituent components to highlight the influence of each on the exergy value. Refer to "Fig. 9" and as far as the same quantity of heat recovery $(274 \mathrm{~kW})$ has been assumed for the system for all cooling capacity, by increase of cooling capacity the recovery efficiency was reduced from $94 \%$ to $48 \%$. However with an assumption of the constant surrounding temperature $\left(25^{\circ} \mathrm{C}\right)$ for the water container and also due to the low quality of the hot water temperature at $70^{\circ} \mathrm{C}$, the effectiveness of the recovered heat was quite low.

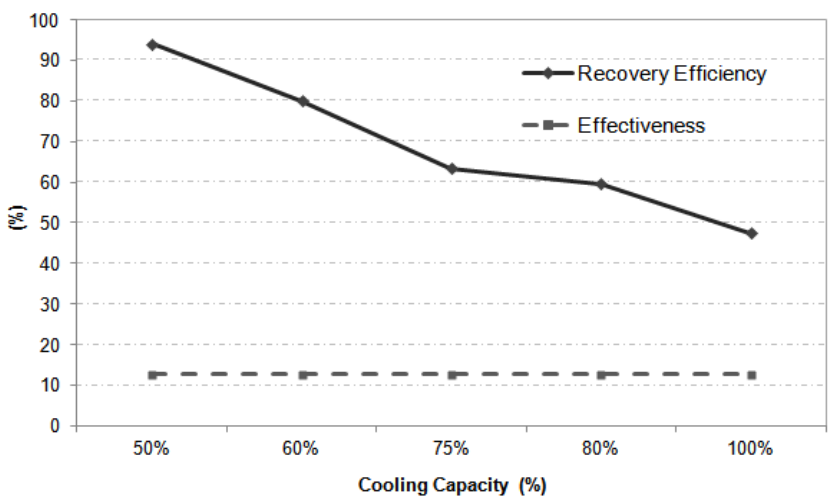

Fig. 9. Recovery efficiency and effectiveness evaluation as a function of chiller cooling capacity.

From the presented results, total recovery potential (TRP) can be calculated from total recovery efficiency and effectiveness of the removed heat from the chiller condenser. Equations "(3)," to "(6)," are applied for calculation of the total recovery potential. As it is illustrated in Fig. 10, due to the low quality of the heat, the overall TRP was quite low for all cooling capacities. Furthermore with higher cooling capacity, TRP has been decreased. Hence to increase the recovery efficiency at higher cooling capacity, the quantity of the recovered heat need to be raised.

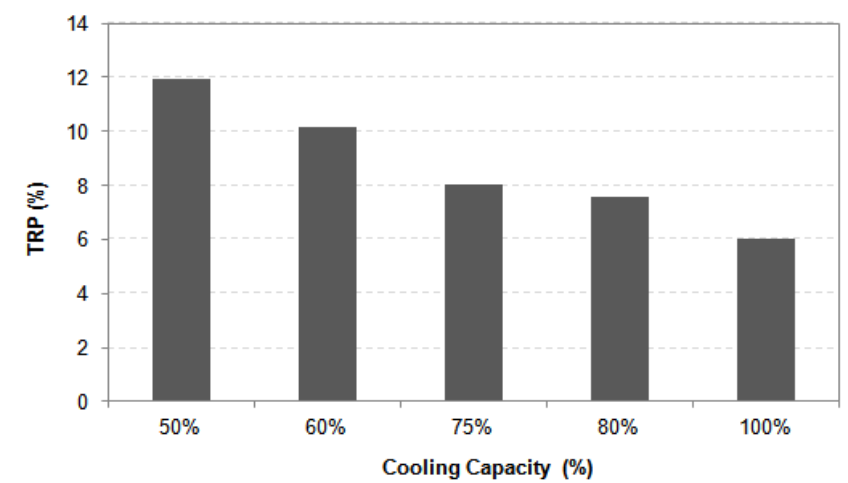

Fig. 10. Comparison of the total recovery potential as a function of chiller cooling capacity.

An appropriately defined exergy and irreversibility analysis can unambiguously characterize the performance of the system components by changing of physical parameters. These results help the engineers to focus on the components with higher exergy destruction and quantify the extent to which modifying such components can influence the performance of other components. However there are some limitations which influence the practical application of the results as are listed follow:

- In general a part of exergy destruction occurring in a component is caused by the inefficiencies of the remaining system components and due to the technical constrains, it is difficult practically to match the related parameters to prevent these losses.

- Due to the technical chiller specifications to reach the required pressure, temperature and the refrigerant flow rate for WHR situation, the reduction of each component irreversibility based on change in physical parameters is 
limited.

- The analysis was conducted with an assumption of steady state condition. However with WHR purpose, the hot water is drained in transient state which would influence the final result and leads to some errors.

- For optimization purpose it should be noticed that the final objective to improve the thermodynamic efficiency in the design of new system such as chiller with WHR has no practical value and should be considered in conjunction with associated minimization of cost and pollutant emissions.

\section{CONCLUSION}

To redesign for heat recovery, an industrial air-cooled refrigeration system has been thermodynamically investigated. For this investigation energy and exergy analysis methodologies have been applied. It was observed that due to change in the system physical parameters (temperature, pressure and refrigerant flow), both $\mathrm{COP}$ and $\mathrm{COP}_{\mathrm{Ex}}$ were lower for the system with heat recovery compare with the conventional chiller. Furthermore total recovery potential was introduced as a resource saving factor. The analysis has been carried out based on recovery efficiency as an energy efficiency factor and the effectiveness which represents the exergy efficiency of the recovered heat. It was found that TRP was quite low and was in reverse relation to the cooling capacity. However at the lower cooling capacity, TRP was higher due to the higher recovery efficiency. Although an improvement of the recovery efficiency is expected by increase of the recovery capacity, owing the low quality of the waste heat leads to TRP does not increase significantly. As a result the established exergy-based approach assists to have better understanding about the direct and indirect resource saving which can be achieved by raising the amount of the low quality recovered heat.

\section{ACKNOWLEDGMENT}

The authors wish to thank Mr. Lang from Mahle Behr $\mathrm{GmbH}$. This work was done and supported as part of a cooling system redesign and improvement in Mahle Behr, Germany.

\section{REFERENCES}

[1] S. Baumgärtner and J. Arons, "Necessity and inefficiency in the generation of waste," Journal of Industrial Ecology, vol. 7, no. 2, pp. 113-123, 2003.
[2] R. Goldstick and A. Thumann, Principles of Waste Heat Recovery, Fairmont Press, USA, 1986.

[3] M. Bendig, F. Maréchal, and D. Favrat, "Defining 'Waste Heat' for industrial processes," Applied Thermal Eng., vol. 61, issue 1, pp. 134-142, 2013.

[4] Y. Ammar, S. Joyce, R. Norman, Y. Wang, and A. Roskilly, "Low grade thermal energy sources and uses from the process industry in the UK.," Applied Energy, vol. 89, issue 1, pp. 3-20, 2012.

[5] I. Dincer and A. M. Rosen, Exergy, Energy, Environment and Sustainable Development, 1st ed. Elsevier: China, 2008, pp. 60-76.

[6] S. T. Lee, "Second-law analysis to improve the energy efficiency of screw liquid chillers," Entropy, vol. 12, pp. 375-389, 2010.

[7] D. Brown, F. Mare'chal, and J. Paris, "A dual representation for targeting process retrofit, application to the pulp and paper process," Applied Thermal Eng., vol. 25, pp. 1067-1082, 2005.

[8] Ö. Kaska, "Energy and exergy analysis of an organic Ranking for power generation from waste heat recovery in steel industry," Energy Conversion and Management, vol. 77, pp. 108-117, 2014.

[9] M. Z. Stijepovic and P. Linke, "Optimal waste heat recovery and reuse in industrial zones," Energy, vol. 36, pp. 4019-4031, 2011.

[10] Waste Heat Recovery: Technology and Opportunities in U.S. Industry, BCS, 2008

[11] B. Bakshi, T. Gutowski, and D. Sekulic, Thermodynamics and Destruction of Resources, 1st ed., Cambridge Uni. Press: USA, 2011, pp. 30-43, 163-186.

[12] A. Jentsch, "A novel exergy-based concept of thermodynamic quality and its application to energy system evaluation and process analysis," Ph.D. dissertation, Dept. Process. Eng., Berlin Univ., 2010.

[13] E. Bilgen, "Takahashi B. Exergy analysis and experimental study of heat pump systems," Exergy, pp. 259-265, 2002.

[14] Heat recovery from chilled water system. Carrier ${ }^{\circledR}, 2008$.

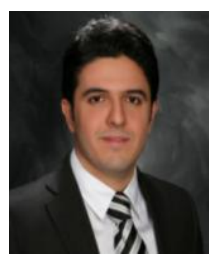

Kamran Taheri is currently a Ph.D student at the University of Stuttgart in Germany. He obtained his B.Sc in environmental engineering from Petroleum University of Tech., Iran in 2008. He obtained his M.Sc in environmental and process engineering from University of Stuttgart, Germany in 2012. His research interest areas are combustion and flue gas control, energy efficiency, life cycle analysis and resource saving.

His $\mathrm{Ph} . \mathrm{D}$ dissertation topic is energy efficiency in manufacturing.

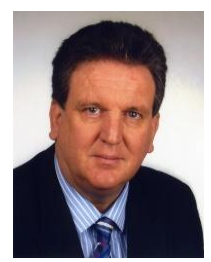

Rainer Gadow is a professor and director of the Institute for Manufacturing Technologies of Ceramic Components at the University of Stuttgart. He finished his bachelor in chemistry with emphasis on technical chemistry of solids at the University of Karlsruhe and then he obtained his master degree in the fields of high-temperature protective coatings and carbon fiber composites in 1981. He received his Ph.D at the Faculty of Chemistry, University of Karlsruhe in 1986.

Prof. Gadow became in 1986 as the head of Research and Development at W. Haldenwanger Technical Ceramics GmbH u. Co. KG, Berlin and Waldkraiburg. He was also a manager of Euroflamm GmbH in Bremen. He was also the managing director of the BDAG surface technology $\mathrm{GmbH}$. 